RESENHA

\title{
Foucault avec Merleau-Ponty: ontologie politique, présentisme et histoire
}

\author{
Paula Nunes Chaves \\ Terezinha Petrucia da Nóbregal (D)
}

REVEL, Judith. Foucault avec MerleauPonty: ontologie politique, présentisme et histoire. Paris: Vrin, 2015. 226p.

Judith Revel é especialista em filosofia francesa do pós-guerra (1945). A autora desenvolve trabalhos acerca dos entrelaçamentos entre história, filosofia e política na tentativa de problematizar o presente, marcando as possibilidades de torções, mudanças e intervenções. É com esse tom de reinvenção, inauguração e ruptura no seio da história defendida em Foucault e Merleau-Ponty que se inscreve sua última publicação, objeto desta resenha, o livro Foucault avec Merleau-Ponty: ontologie politique, présentisme et histoire (Foucault com Merleau-Ponty: ontologia política, presentismo e história). Publicada no ano de 2015, a obra vem nos presentear com a história das clivagens e tensões que fizeram parte da produção do pensamento histórico, político, ético e estético em ambos os filósofos.

A edição é organizada em uma introdução e duas partes, cada uma composta de três capítulos consagrados ao pensamento de um dos filósofos citados no título da obra, e finalizada em uma conclusão. No livro há uma vasta bibliografia de Foucault e Merleau-Ponty, dialogando também com Derrida, Nietzsche, Deleuze, Saussure. Nota-se a referência ao estruturalismo e pós-estruturalismo francês, conforme nos mostra a análise de Dosse (1991, 1992), que, mesmo não sendo citado por Revel, apresenta importante contribuição ao contexto da história das ideias do pensamento francês naquele período.

$\mathrm{Na}$ introdução, a autora assinala a compreensão de filosofia e de história enquanto domínios indissociáveis e o esboço de uma nova atitude filosófica de interrogação do mundo em Foucault e em Merleau-Ponty. Revel observa uma concepção de história pautada na reversibilidade e na simultaneidade existentes entre determinação e liberdade, pontuando a figura do quiasma em Merleau-Ponty - marcadamente nas notas de Le visible et l'invisible (O visível e o invisível)

'Universidade Federal do Rio Grande do Norte, Natal, RN, Brasil. 
(Merleau-Ponty, 1964) - como possibilidade de compreensão das relações intrínsecas entre determinação e invenção concernente à história, aos modos de pensamento e aos sistemas de verdade. Segundo a autora, essa concepção influenciou a filosofia de Michel Foucault.

A primeira parte do livro, intitulada "Foucault, história e atualidade", é composta de três capítulos que fornecem um panorama do pensamento histórico defendido por esse pensador. Ao percorrer essa trajetória, é possível perceber os deslocamentos do pensamento filosófico e metodológico de Foucault, que caminha de uma periodização dos fatos históricos — visível em sua arqueologia —, passando pela genealogia para finalmente chegar a uma atitude. Esta, por sua vez, certamente mais próxima ao regime ético, no qual se busca superar a ideia de um sistema de pensamento como sendo um episódio na história das ideias para esclarecer processos que instauram novas formas de racionalidade, de técnica, de autonomia e de autoridade do saber. Essa atitude trans-histórica seria uma saída da história, tal como Foucault compreendeu em sua arqueologia e genealogia.

Nessa primeira parte do livro, Revel detalha o projeto foucaultiano de realizar uma história dos sistemas de pensamento, bem como de apontar essa mudança rumo a uma abordagem da trans-historicidade enquanto atitude metodológica, epistemológica e ética que inaugura a figura da attitude, ou seja, uma forma de pensamento e de ação que engaja uma ética, um pensamento do descontínuo, um éthos, uma vida filosófica.

A partir dessa noção de atitude, outra noção tem lugar: a diferença na história. Assim, surge a ideia de uma descontinuidade, de uma interrupção possível no seio do presente, uma possibilidade de construção e criação para além do que se encontra posto. Trata-se de uma diferenciação, uma ruptura e uma reinvenção das determinações no curso deste tempo presente, que se dá, para Foucault, especialmente nos domínios dos modos de subjetivação enquanto atitudes ético-políticas e estéticas.

A filósofa aponta esse novo tipo de análise histórica foucaultiana da década de 1970, esse éthos e atitude crítica para com os modos de vida como um gesto político de resistência, posto que este inventa outros mundos, outras formas de vida, valendo-se de uma diferenciação de si e da experimentação de uma filosofia viva (Revel, 2015). Abrem-se então outras possibilidades de pensar a relação entre estética e política na contemporaneidade dentro de uma história que inaugura modos inéditos de trabalhos sobre si, metamorfoses e experimentações do corpo.

Revel destaca em Foucault uma característica extremamente importante da contemporaneidade: os modos de subjetivação, de construção de si pelo outro e por nós mesmos, destacando-se a possibilidade de invenção e constituição de si como sujeito e a dimensão ético-política constitutiva desse processo. Podem ser citadas várias formas de subjetivação contemporâneas, de projetos subversivos de construção e transformação de si mesmo no interior das determinações históricas, como os domínios do gênero e da sexualidade; as diversas intervenções sobre o corpo por meio de cirurgias de transgenitalização; o domínio da body art, das tatuagens, piercings, entre outras formas e modos de vida inauguradores de outras subjetividades.

A segunda parte do livro, "Merleau-Ponty político", contém uma narrativa consistente da formação do pensamento político desse filósofo. No ensaio La guerre 
a eu lieu (A guerra aconteceu), publicado no primeiro número da emblemática revista Les Temps Moderns, em outubro de 1945, Merleau-Ponty assinala que o mundo não poderia ser mais o mesmo após tal barbárie. A partir daquele momento seria preciso "sujar as mãos", e os filósofos não poderiam se eximir de tal atitude, apontando um entrelaçamento entre história, filosofia e política.

Nesse texto, Merleau-Ponty despede-se de uma determinada maneira de compreender a filosofia e a história, rejeitando a ideia de uma consciência nua ou de uma história como relato de fatos verdadeiros ou determinados: a história é antes de tudo angústia, aproximando-se intensamente de uma perspectiva subjetiva, pensamento este que seguramente influenciou Michel Foucault, seu futuro ouvinte nas lições que proferiu na Sorbonne e no Collège de France (Merleau-Ponty, 1945).

De fato, uma vez que o conflito havia terminado e as atrocidades cometidas começavam a ser reveladas ao mundo, em vez de postular o fim da história, a interdição da confiança nos homens ou a saída por meio de uma consciência reflexiva - como muitos fizeram após a guerra -, Merleau-Ponty parte da própria vida tal como ela é construída no cotidiano, nos gestos e nas relações. "É essa vida que vai se tornar o espaço do político, porque é ela que tece inelutavelmente a trama da história; e que pertence a nós, os vivos, para construir paisagens futuras" (Revel, 2015, p. 143, tradução nossa).

Essa compreensão de política é uma das responsáveis pelo rompimento entre Merleau-Ponty e Sartre, fato então retratado no livro de Revel. A autora assinala que Merleau-Ponty não entrou no terreno objetivo da política, desenvolvendo uma compreensão oposta à de Sartre e fundada na noção de expressão, sendo acusado por esse último de abandonar a política em detrimento de uma filosofia puramente especulativa e subjetiva, sem a existência de um engajamento ou ação. Uma das argumentações mais importantes de Revel nessa publicação encontra-se na afirmação de que o afastamento entre esses dois filósofos não somente foi determinante para o pensamento filosófico e político Merleau-Ponty, mas representa uma antecipação de temas que Foucault irá desenvolver vinte anos mais tarde, atentando para a influência das postulações merleaupontianas em seu pensamento, ligação esta por vezes esquecida.

Em Merleau-Ponty encontra-se o esboço de uma filosofia da expressão que possui incidência política. É essa compreensão de política enquanto operação expressiva e inventiva de significações que Revel (2015) discute, apoiada em uma reflexão sobre o pensamento histórico e estético em Merleau-Ponty. O conceito de expressão é, para esse filósofo, um pensamento de inauguração e de criação. Seu interesse pela arte, literatura e cinema é uma forma de pensar as tensões do mundo e as dobras da existência (Imbert, 2005).

Revel (2015) argumenta que o pensamento político de Merleau-Ponty nunca recebeu a atenção que merecia, mas que ele deu à política um fundamento filosófico. E talvez este seja um dos grandes méritos de seu livro: trazer à tona uma compreensão de política relacionada à ordem da linguagem, que atravessa a vida cotidiana dos gestos, das expressões e do corpo, fazendo desses espaços interrogativos nos quais se tece a trama da história uma passagem do linguístico, da expressão e do estético para o político. 
Ao final do livro, a autora conclui que em ambos os filósofos se encontra uma forma de pensar a história balizada na simultaneidade entre determinação e liberdade. Revel aponta direções para a ampliação dos debates filosóficos e políticos dos anos 1950 e 1960 e para novas interrogações dos problemas já formulados sobre a história, como a figura do quiasma e a concepção de uma história do pensamento que está sempre se fazendo.

Já no título do livro, Foucault com Merleau-Ponty, Revel (2015) reconhece na construção do pensamento de Foucault a influência da filosofia de Merleau-Ponty para além das análises que o restringem à sua "fenomenologia da percepção", especialmente no tocante à historicidade do presente e aos processos de subjetivação que se operam como expressão estética e política.

\section{REFERÊNCIAS}

Dosse, F. Histoire du structuralisme. Paris: La Découverte, 1991.v. 1.

. Histoire du structuralisme. Paris: La Découverte, 1992.v. 2.

Imbert, C. Maurice Merlau-Ponty. Paris: ADPF, 2005.

Merleau-Ponty, M. La guerre a eu lieu. Les Temps Moderns, Paris: Éditions Gallimard, n. 1, p. 48-66, oct. 1945.

. Le visible et l'invisible. Paris: Gallimard, 1964.

Revel, J. Foucault avec Merleau-Ponty: ontologie politique, présentisme et histoire. Paris: Vrin, 2015.

\section{SOBRE AS AUTORAS}

Paula Nunes Chaves é doutoranda em educação pela Universidade Federal do Rio Grande do Norte (UFRN). Professora do Instituto Federal de Educação, Ciência e Tecnologia do Rio Grande do Norte (IFRN).

E-mail: paulinha_nunes3@hotmail.com

Terezinha Petrucia da Nóbrega é doutora em educação pela Universidade Metodista de Piracicaba (UNIMEP). Professora da Universidade Federal do Rio Grande do Norte (UFRN).

E-mail: pnobrega68@gmail.com

Recebido em 29 de maio de 2017 Aprovado em 19 de julho de 2017 